\title{
How Smart City practices create comfortable environments for low mobile population groups
}

\author{
Larisa Vlasenko $^{{ }^{*}}$ \\ ${ }^{1}$ Moscow State University of Civil Engineering, Yaroslavskoe shosse, 26, Moscow, 129337, Russia
}

\begin{abstract}
The article covers the arrangement of comfortable conditions for physically challenged and low mobile residents in urban environments. Currently, these social categories are discriminated in urban societies. Contemporary cities, their infrastructure fail to satisfy their needs. Their ability to move around and fulfill their potential in urban spaces is limited. In the article, the author provides the findings of the sociological survey, conducted in Novokuznetsk, Kemerovo region, in 2015 - 2016. The survey's mission was to find out whether the principles of reasonable adjustment of an urban environment to the needs of various groups of residents needed to be integrated into the public policy. This problem turns particularly relevant in the context of the development and introduction of the Smart City practices.
\end{abstract}

\section{Introduction}

When analyzing the problems, typical for the urban construction industry $[1,2,3]$, researchers draw particular attention to the development of the urban infrastructure with account for the needs of physically challenged and other low mobile residents. The researchers urge for the transformation of the urban infrastructure not only to assure its architectural beauty and harmony, but also to assure its economic, political, and social expediency, rationality and comfort for these groups of residents.

According to M. Castells, contemporary cities are part of the process of collective consumption, which is an important feature of industrial capitalism. Major construction companies, banks, large corporations, government agencies, acting as investors into construction projects, produce their influence on the urban development, construction of office buildings, shopping malls, residential houses and roads. They determine the urban exterior and infrastructure, but they can hardly accommodate the interests of urban residents (including physically challenged individuals). M. Castells believes that the exterior of a contemporary city is the product of market forces and power. He thinks that problems of cities and urban environments vitalize the social environment and force various social groups to fight for the enhancement of their living conditions. These problems include poor housing facilities, polluted air, unavailability of greenery, construction sites, deteriorating the exterior of the community, etc. [4] To my mind, the major problem

Corresponding author: vllv@inbox.ru 
consists in the unavailability of any comfortable environment satisfying the needs of physically challenged and low mobile residents.

It is generally admitted that a human being is nurtured by his/her environment, composed of socialization agents, culture, and nature. The capabilities of healthy individuals are not limited; healthy persons are fully integrated into social processes, but the social integration and personal fulfillment of physically challenged residents are hardly feasible, unless there is some comfortable infrastructure and friendly urban environment in place. $[5,6,7]$

New construction facilities $[8,9]$ fail to take account of the legislation, requesting a barrier free environment for physically challenged residents, both at the stage of design and construction. These laws are often formal, and government authorities fail to control their compliance. Therefore, it is the social environment, rather than the physical impairment, that discriminates these social groups . [10] and builds barriers, depriving physically challenged residents of their social rights and implanting inequality.

It is noteworthy that physically challenged and low mobile individuals (elderly persons, moms with baby strollers, small children, etc.) are the people who find that any barriers (steps, traffic areas, public transport, ticket gates, etc.) in the urban space are insurmountable; these barriers may prevent their effective involvement in the public life together with other residents.

According to the Federal State Statistics Service, as of the beginning of the year 2016, $12,750,000$ physically challenged individuals resided in the Russian Federation, and 617,000 of them were children. Since 2010, the number of physically challenged individuals has been going down in Russia. Since then, the Government of the Russian Federation has been implementing the Target Federal Programme for the Social Support of Physically Challenged Individuals. One of its missions is to set the stage for the rehabilitation and integration of physically challenged individuals into the Russian society. However, this Programme has not solved the problem of the barrier free environment for physically challenged individuals and other low mobile population groups.

In 2008, the Russian Federation signed the UN Convention on the Rights of Persons with Disabilities, which says that each signatory must provide disabled persons with access to transport, communications, and information (including information and communication technologies and systems), facilities and services, available or rendered to other population groups.

The Federal Programme on the Barrier Free Environment, designated for 2011 - 2015 and approved in late 2009, serves as the basis for the implementation of this Convention. The mission of this Programme is to make sure that physically challenged individuals have access to the social environment, education, sport, tourism, information and communications.

\section{Materials and Methods}

The objective of our research project is to study the problem of developing a barrier free environment for disabled and low mobile residents of small towns, which are different from megalopolises (for example, Novokuznetsk, having 551,253 residents), and to explore the opportunities offered by the Smart City practices to make the urban environment more comfortable. Towards this end, in 2015 and 2016, a group of researchers, composed of the lecturers of the Moscow State University of Civil Engineering (MSUCE) and the Siberian State Industrial University (SSIU) launched a sociological survey.

The primary survey was based on the expert poll and document analysis as the core methods of sociology. Besides, the research group employed the simulation method. The pool of experts was composed of the specialists and officers employed in the 
areas/industries, responsible for the development of the barrier free environment in Novokuznetsk. Some of the experts were officers of the urban authorities; others were disabled residents.

The expert poll comprised the following four main sections:

- assessment of the Barrier Free Environment Programme performance;

- identification of the most frequent set of problems addressed by disabled residents to the urban authorities;

- identification of the set of actions taken by the urban authorities to implement this Programme;

- identification of problems, arising in the process of implementation of the Barrier Free Environment Programme.

The project developers employed the document analysis method to assess the efforts of the municipal authorities exerted in the process of promotion and implementation of this Programme and to evaluate the ability of Smart City practices to improve the urban environment for disabled and low mobile residents.

\section{Results}

How can these goals be attained and how can the local authorities help disabled and low mobile residents to get integrated into the social environment and take the rightful place there? These are the questions asked of our experts.

Some experts, employed with the Novokuznetsk urban authorities, responded that the issue of the barrier free environment was monitored on the ongoing basis and everything was done to develop a barrier free environment in this town, while the other group of experts was on the other side of the fence.

Let's focus on some of their comments:

"Now the condition of the barrier free environment is HOPELESSLY BAD! Some positive changes are there, but I cannot leave home all by myself, I need help." (Expert 5)

"Not all construction facilities are exposed to expert evaluations, while customers and investors do not want to spend any extra money, and even if they do something, they do it formally; there is indifference in place ..." (Expert 7).

"The main reason for the inaccessible environment is the human factor, lack of funding, lack of any control over the development of the barrier free environment, lack of any concern, and any person may have this problem." (Expert 4).

"I give a " $C$ " mark to the condition of the barrier free environment in our town, because it does not obtain sufficient funding or other resources, and, on the whole, development of the barrier free environment is not the top priority investment for our authorities. This year, no investments will be made into cultural events, and it's sad. But the government has many problems to solve, and the barrier free environment is not number one. This happens because human conscience is not willing to develop this environment. Even if some facilities are barrier free, they are scarce, while the main problem of the barrier free environment consists in the unavailability of any comprehensive solution." (Expert 5).

"My recommendations are as follows: first of all, we need to change the mindset of our residents, we need to get young people to know that the barrier free environment is a must for everybody, not only for disabled people. A barrier free environment is the climate of the society. If we sit down more often to see what our children see, we will be able to notice the problems which are hardly visible at first glance. A barrier free environment is the best solution which is convenient for everyone. My recommendations are that we need to change the public conscience, to realize the problem significance, because any problem solving depends on each person and the whole society. "(Expert 5). 
The findings of the expert poll have proven the need for supplementary funding and targeted outreach efforts. It is necessary to take account of the impact produced by the accessibility factors on the mobility, employment, social activity, health, and social welfare of disabled individuals.

The international expertise has proven that the government investments made into the arrangement of the barrier free access to social security facilities (communications, transport, educational and healthcare institutions, etc.) for disabled residents, to help them take control of their lives, choose their goals and attain them, pay back through their proactive involvement in varied social and production processes.

The comprehensive approach and Smart City practices are applied to develop a barrier free environment for all social categories in Moscow and some other Russian cities and towns, but in the Russian regions, this process is at its initial stage at the moment. The experts believe that the allure of "the living environment" will go up through the introduction of the Smart City concept in urban areas.

The introduction of information technologies and systems into the urban environment serves as the fundamental principle of the Smart City. There is no doubt that this approach will improve the system of management and interaction between the authorities and the society, improve the quality and efficiency of the urban authorities, facilitate a qualitative improvement in the lives of urban residents, remove barriers from the urban space and environment.

The analysis of the secondary information and the findings of the expert poll have identified the following vital problems, preventing the generation of the barrier free environment for disabled residents: 1) disagreement between government authorities responsible for the generation of the barrier free environment, 2) inefficient coordination and interaction between government authorities, other management authorities and business entities in respect of the barrier free environment, 3) imperfect legislation, 4) unavailability of any legal route for the involvement of supervisory bodies and public associations of disabled residents in the generation of a barrier free environment, 5) unavailability of any road map or strategy for the generation of tolerance to disabled persons in the society, 6) unavailability of the proof of the economic feasibility/efficiency of investments made into the barrier-free environment through the Smart City project.

\section{Discussion}

P. Drucker introduced the "smart" notion. In his book "The Practice of Management", P. Drucker studies efficient management. He interprets this notion and regards this abbreviation as a combination of five words, or the basic elements of efficient management: specific, measurable, achievable, realistic, and time-based. In the course of their work, researchers and urban specialists applied this term and interpreted it as "the manageable city".

Later, the Smart City term was widely used in various meanings. Most of them can be reduced to the following definition: the Smart City is a combination of advanced technologies and solutions improving the quality of the urban life and helping the urban economy to efficiently use any resources at its disposal.

Multiple researchers drew attention to urban social problems and to the employment of innovative technologies. The UN developed the Programme, designated for the implementation of the Smart City project in various countries. The developers of this Programme believe that the introduction of smart technologies streamlines the capacity of urban resources, saves cash and, thus, offers higher quality services to various groups of residents. Even inexpensive technologies, if and when introduced, can make a positive impact on the urban life's quality. 
Presently, this Programme is being implemented in several major cities, including New York City, Boston, San-Francisco, Amsterdam, Rome, Tokyo, Singapore, Copenhagen, and Vienna. In Russia, both capitals (Moscow and St.Petersburg) have joined this Programme, SMART City Kazan is being proactively built in Tatarstan. Vladivostok and Voronezh also serve as the pilot sites of the projects developed by the Japanese specialists.

Nonetheless, "a smart city" should never be treated as "a machinelike city", or a set of sensors, robots, other devices, shaping the urban environment and capable of making decisions, which are efficient at all times. A truly smart city is impossible without the involvement of humans, without the development of a comfortable environment for their lives. These changes in the urban environment, its infrastructure, caused by innovative technologies introduced into the urban economy, will definitely improve the city's accessibility and comfort for disabled and low mobile residents.

"Management" is a vital constituent of a smart city. Its main objective is to coordinate and control each urban sub-system, including transport, utilities, safety, retail trade, power consumption, and healthcare. "Mobility" is another constituent, which is equally important. It is vital both for residents with disabilities and low mobile residents.

The idea of a barrier free city is regularly reduced to "ramps instead of stairs", "the elevator to the underground", and a "folding footboard in urban buses". Rather, the notion of a barrier free city should comprise the organization of the urban transport flow ensuring maximal comfort and safety for urban residents. These evident and appropriate solutions have been implemented in many countries years ago. Having these principles in mind, Japan has turned into the country which is acknowledged ideal for people with disabilities. However, Russia, being the largest country in the world, has no potential to implement this project in each of its cities and towns, although advanced intelligent technologies can get adjusted to specific urban features and get entrenched into the lives of any city, from a megalopolis to a small town. Today Moscow (Skolkovo) and St.Petersburg (New Bank) are implementing the projects which will extend the range of opportunities for residents with disabilities. For example, the New Bank project is an attempt to create a universal environment on the basis of the principle of tailored management. By pressing the button inside his/her flat, a disabled person can make an appointment with his/her doctor, utility services officer, pay his utility bills, obtain the weather forecast or the timetable for local and long distance trains.

\section{Conclusions}

A joint effort of government authorities and other institutions (including educational and healthcare institutions, business entities), public organizations of disabled residents and the whole society, is needed to solve the above problems and to have a successfully functioning barrier free environment in a city.

We can propose a number of actions which may improve the situation in the regions: 1) it is necessary to control design and construction processes with account for the concerns of disabled urban residents and guests; regular independent appraisals of construction, design and restructuring projects must be performed with the involvement of public organizations of disabled residents and all government authorities involved in the generation of the barrier free environment; 2) it is necessary to generate the barrier free environment through the application of Smart City practices; 3 ) there is a need to have specialists in the barrier free environment trained; $[11,12] 4$ ) there is a need to increase the number of jobs for disabled residents, and to have supplementary incentives provided to employers; it is necessary to incorporate production enterprises which will recruit disabled individuals; 5) it is necessary to have the needs of disabled residents covered by the media, etc.[13] 
It is noteworthy that Smart City practices may be employed to implement efficient rehabilitation programmes for disabled residents, inter alia, through the better accessibility of social security, employment, education, healthcare and sports institutions, as well as transport, information and communications facilities. Smart Cities should both provide better access to "smart" devices for all social categories and teach them to use each device.

Smart City projects have penetrated into multiple contemporary megalopolises. This is a deeply integrated system, composed of video surveillance networks, public services providers, intelligent transportation systems, electronic police, electronic education, electronic healthcare, etc. However, many Russian cities and towns are not integrated into this process. The state of affairs is clear, but changes are needed. The proactive generation of the barrier free environment is only possible if and when its efficiency is scientifically valid and proven by the in-depth research. [14] In this case, its efficiency is understood as the balance of costs and deliverables. The researchers drafted a research manuscript covering the issues raised in the research project. [15]

\section{References}

1. L. Mumford, The culture of the cities ( Greenwood Press Reprint, 1981).

2. K. Lynch, The image of the City (The MIT Press, 1960).

3. J. Jacobs, The death and life of great American cities (Random House, 1961)

4. M. Castells, The City and the Grassroots: A Cross-cultural Theory of Urban Social Movement. (Berkeley: University of California Press, 1983).

5. I.P. Pryadko, International Journal of Applied Engineering Research 10(21) 4214742152 (2015).

6. I.P. Pryadko. Construction:Scuence and Education , 1, 1 (2013)

7. V.L. Glazychev, A city without borders (Territoriya Budushchego Publ, 2011).

8. M.B. Vilkovsky Sociology of the Architecture («Russian Avantgarde» Heritage Preservation Foundation, Moscow (2010).

9. L.B. Kogan, Urbanization. Evolution of Research and Technology and the Working Class (Nauka Publ, 1972).

10. E. A. Shnyrenkov E.A. Bulletin of The Institute of Sociology 2 (13), 17-29 (2015).

11. A. Ishkov, T. Magera. Procedia Engineering, 117, 148 - 153 (2015)

12. Ishkov A.D., Leontev M.G. Procedia Engineering, 117, 142-147. (2015)

13. N.G. Miloradova, A.D. Ishkov, Procedia Engineering 117, 246-251 (2015).

14. Z.I. Ivanova, O.V. Yudenkova, Applied Mechanics and Materials, 737, 909-912 (2015)

15. S.G. Terskova, L.V. Vlasenko,. Economics and Entrepreneurship 2(1), 613-617 (2016) 